\title{
The relationship between nasal septal deviation and anatomical variations of the paranasal sinus
}

\author{
Oğuzhan Dikici $\odot$, Osman Durgut $\odot$
}

Department of Otorhinolaryngology, University of Health Sciences, Bursa Yüksek Ihtisas Training and Research Hospital, Bursa, Turkey

\section{ABSTRACT}

Objectives: The aim of this study was to determine the relationship between septum deviation and anatomic variations of the paranasal sinus.

Methods: A total of 157 ( 79 males, 78 females) patients between the ages of 17 and 77 years (mean age: 33.7 \pm 14.9 years) were included in the study. Using paranasal sinus computed tomography imaging, anatomical variations including nasal septal deviation, Agger nasi cells, Haller cells, Onodi Cells, sphenoid sinus pneumatisation, paradoxical middle turbinates, middle turbinate pneumatisation, maxillary sinus septa,vertical septa in the sphenoid sinus, optic nerve dehiscenceand cribriform plate lamina lateralis height were evaluated. Results: Agger nasi cells were present in $47.1 \%$ of cases, Haller cells were seen in 5\% of cases and Onodi cells were observed in $23.6 \%$ of cases. In $70.1 \%$ of cases, one vertical septa in the sphenoid sinus was observed. Maxillary sinus septa was observed in $16.5 \%$ of cases. There was a significant negative correlation between the female gender and increased sphenoid sinus pneumatisation $(p=0.035)$. There was a positive correlation between maxillary sinus septa and the presence of Onodi cells $\left(p^{\text {right }}=0.045, p^{\text {left }}=0.017\right)$. There was also a negative correlation between maxillary sinus septa and sphenoid sinus pneumatisation $\left(p^{\text {right }}=0.001, p^{\text {left }}=\right.$ 0.005).

Conclusions: In our study, we found that maxillary sinus septa, Agger nasi, Haller cells, cribriform plate lamina lateralis height, sphenoid sinus septation and Onodi cells were interrelated. We recommend that surgeons evaluate patients with these variations to prevent complications.

Keywords: Agger nasi, Haller cells, Onodi cells, sinus surgery, maxillary sinus septa

$\mathrm{F}$ unctional endoscopic sinus surgery (FESS), commonly used in the surgical treatment of pathologies of the sinuses, is often performed to improve the patient's comfort. To avoid complications during this procedure, all anatomic variations in the patient must be known and well described [1]. The anatomical layout of paranasal sinuses has been well established since the $19^{\text {th }}$ and early $20^{\text {th }}$ centuries [2]. Variations of anatomical structures within the ostiomeatal region can predispose individuals to paranasal sinus patholo- gies. Several sinonasal anatomical variations can be observed via paranasal sinus computed tomography (PSCT) [3]. The introduction of computed tomography (CT) as a diagnostic tool has improved the definition of these anatomical variations [1], and advances in FESS and imaging technology have increased the importance of understanding the anatomical structure of the paranasal sinus [2]. Multiplanar high resolution CT of the paranasal sinuses provides a precise and reliable preoperative roadmap for endoscopic sinus sur- 
geons[2]. CT is an imaging modality recognised as the gold standard for evaluating patients before FESS. The evaluation of anatomic variations using CT is important in both preoperative and intraoperative periods to avoid complications and improve operative success [1].

Anatomical variations in the anterior ethmoid sinus that result in a narrowing of the middle meatus include the presence of a large ethmoid bulla, a large concha bullosa, a paradoxical middle turbinate, an uncinate process bulla and a nasal septal deviation. Lateral deviation ofHaller cells and the uncinate process narrow the infundibulum. Septal pneumatisation in the form of an anterior extension of the sphenoid sinus can narrow the sphenoethmoid recess, which may contribute to the occurrence of posterior ethmoid and sphenoid sinus diseases and increase the chances of future surgical complications at these sites [4]. CT is the preferred method of examination for chronic sinusitis cases, as it enhances the surgeon's vision of the sinonasal cavity and provides a roadmap for surgery. It can enhancelocalisation of the sinus pathology when taken coronally or axially at 3-5 mm intervals. CT imaging performed in the coronal plane provides the most information for an endoscopic sinus surgery [5].

The aim of this study was to determine the relationship between septum deviation and anatomic variations of the paranasal sinus.

\section{METHODS}

This retrospective study was conducted at the Department of Otorhinolaryngology of Health Sciences University Bursa Yüksek Ihtisas Training and Re- search Hospital. The study was approved by the ethics committee of the same hospital with number 2011KAEK-25 2019/02-12.

PSCT scans were examined retrospectively and evaluated by otorhinolaryngologists at the Department of Otorhinolaryngology of our hospital. A total of 157 (79 males, 78 females) patients aged between 17 and 77 years old (mean age: $33.7 \pm 14.9$ years) were included in the study. Exclusion criteria for this study were previous history of skull base or paranasal sinus surgery and congenital facial anomaly. In PSCT images, variations such as Agger nasi, Haller cells, Onodi Cells, (Fig. 1a-c) sphenoid sinus pneumatisation types, middle turbinate pneumatisation, cribriform plate lamina lateralis height (Fig. 2), paradoxical middle turbinate (Fig. 3), maxillary sinus septa (Fig. 4),vertical septa in sphenoid sinus, optic nerve dehissance and nasal septal deviation, were evaluated.

We classified sphenoid sinus pneumatisation in the coronal plane into three types, based on the classification described by Vaezi et al. [6]. In the coronal type 1 or previdian, the pneumatisation extends from the midline to the medial edge of vidian canal. In the coronal type 2 or prerotundum, pneumatisation extends to the lateral edge of foramen rotundum; and in the coronal type 3 or postrotundum, the pneumatisation extends laterally to the foramen rotundum [6].

Cribriform plate lamina lateralis height was evaluated and classified into three types. Measurements between 1 and $3 \mathrm{~mm}$ were classified as type 1, between 4 and $7 \mathrm{~mm}$ as type 2 and between 8 and $16 \mathrm{~mm}$ as type 3 [7].

The location of any deviation was classified as anterior, posterior or anteroposterior. The deviation side was either right or left. Septal deviation was divided

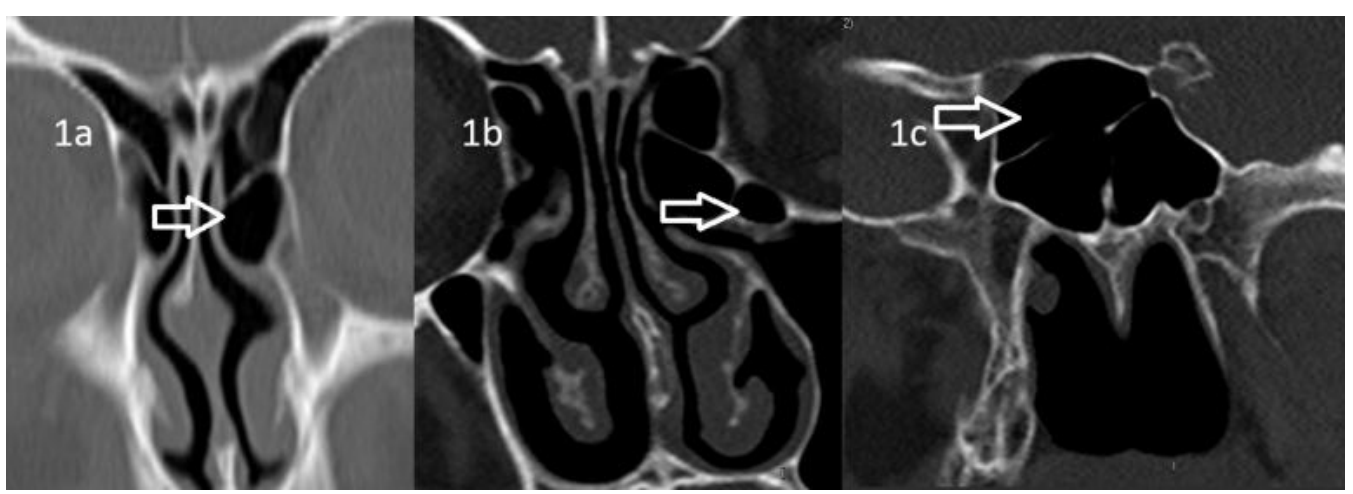

Fig. 1. (a) In coronal section of the PSCT, Agger nasi cell (arrow). (b) In coronal section of the PSCT, Haller cells (arrow) and (c) In coronal section of the PSCT, Onodi cell (arrow). PSCT = paranasal sinus computed tomography 


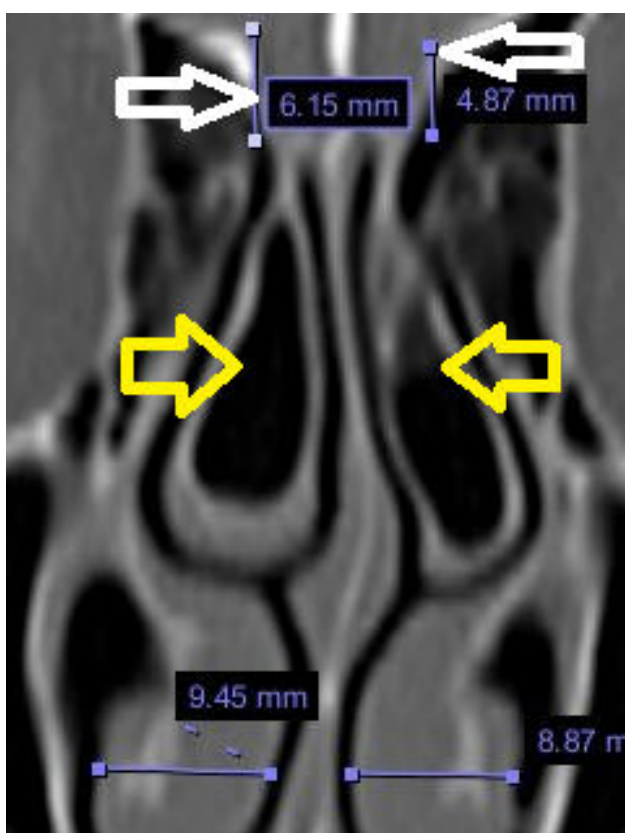

Fig. 2. In coronal section of the PSCT, Concha bullosa (yellow arrows) and measurement of crybriform plate lamina lateralis depth (white arrows). PSCT = paranasal sinus computed tomography

into seven types according to the Mladina classification [8].

\section{Statistical Analysis}

The SPSS software (ver. 23.0) was used for statistical calculations. Both Pearson'scorrelation test and the Kruskal-Wallis test were used. A $p$ value of $<0.05$ was considered to indicate statistical significance.

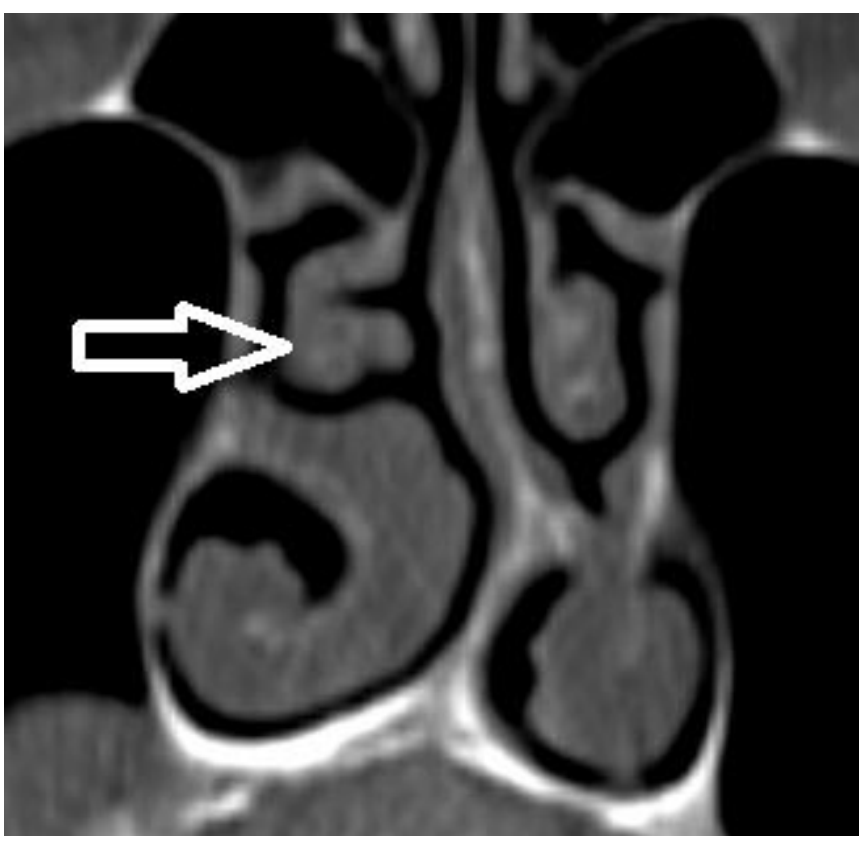

Fig. 3. In coronal section of the PSCT, right paradoxical middle turbinate (arrow). PSCT = paranasal sinus computed tomography tomography

\section{RESULTS}

The deviation was located on the right side in 72 (45.9\%) patients and on the left side in $83(52.9 \%)$ patients. There was deviation on both sides in $1(0.6 \%)$ patient. The deviation was located in the anterior part in $35(22.3 \%)$ patients, in the posterior part in 46 $(29.3 \%)$ patients and the anteroposterior part in 73

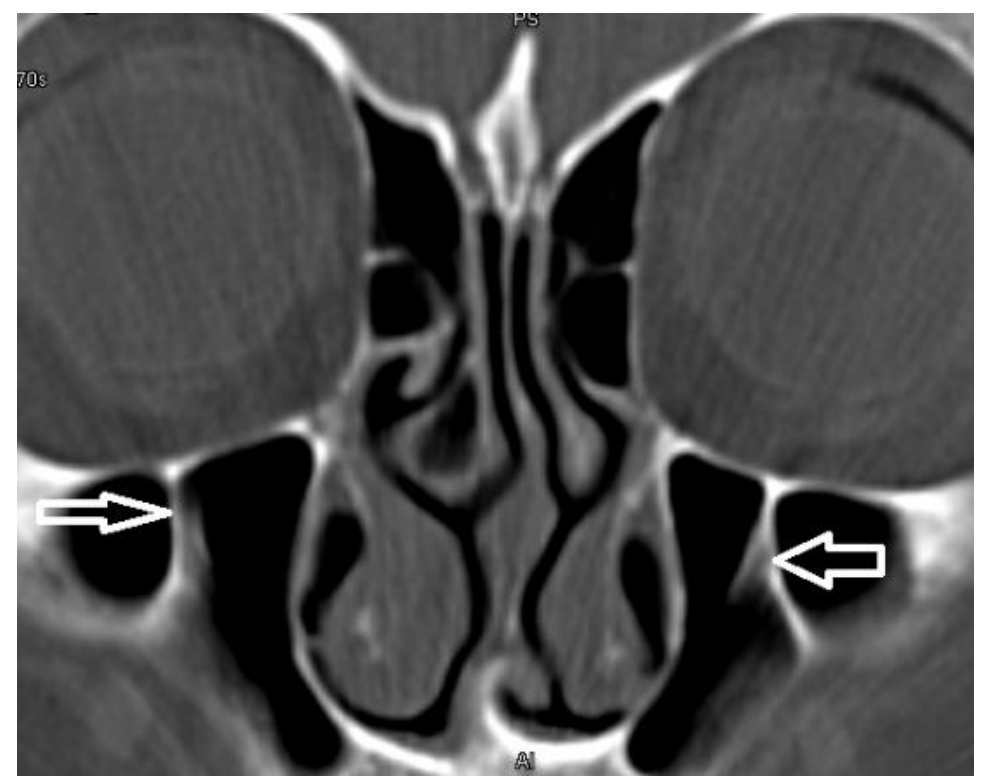

Fig. 4. In coronal section of the PSCT, maxillary sinus septa (arrows). PSCT = paranasal sinus computed tomography 
(46.5\%) patients. The Mladina classification results were as follows: Type 1 in 61 (38.9\%) patients, type 2 in $62(39.5 \%)$ patients, type 3 in $17(10.8 \%)$ patients, type 4 in $3(1.9 \%)$ patients, type 5 in $8(5.1 \%)$ patients and type 6 in $5(3.2 \%)$ patients.

Agger nasi cells were found on the right side in 80 (51\%) patients, on the left side in $80(51 \%)$ patients and on both sides in $74(47.1 \%)$ patients. Haller cells were found on the right side in 13 (8.1\%) patients, on the left side in $15(9.6 \%)$ patients and on both sides in $8(5 \%)$ patients. Onodi cells were found in $37(23.6 \%)$ patients. There was no sphenoid sinus septum in 6 $(3.8 \%)$ patients, 1 vertical septum in the sphenoid sinus in $110(70.1 \%)$ patients, 2 vertical septa found in the sphenoid sinus of $30(19.1 \%)$ patients and 3 vertical septa found in the sphenoid sinus of $11(7 \%)$ patients. Sphenoid sinus pneumatisation classification results were as follows: Type 1 in 74 (47.1\%) patients, type 2 in $58(36.9 \%)$ patients and type 3 in $25(15.9 \%)$ patients. There was optic nerve protrusion in to sphenoid sinus in $42(26.8 \%)$ patients. Maxillary sinus septa was located on the right side in $30(19.1 \%)$ patients, on the left side in $34(21.7 \%)$ patients and on both sides in $26(16.5 \%)$ patients. Paradoxical middle turbinate was present on the right side in $19(12.1 \%)$ patients, on the left side in $13(8.3 \%)$ patients and on both sides in $9(5.7 \%)$ patients. A secondary middle turbinate was found in $1(0.6 \%)$ patient.

Concha bullosa was found on the right side in 88 (56.1\%) patients, on the left side in $84(53.5 \%)$ patients and on both sides in 69 (43.9\%) patients. Concha bullosa found on the right side was lamellar in 46 $(26.3 \%)$ patients, bullous in $7(4.5 \%)$ patients and bullolamellar in $35(22.3 \%)$ patients. Concha bullosa found on the left side was lamellar in $47(29.9 \%)$ patients, bullous in $4(2.5 \%)$ patients and bullolamellar in $35(22.3 \%)$ patients.

Cribriform plate lamina lateralis height was $6.1 \pm$ $2.18 \mathrm{~mm}$ on the right side and $5.88 \pm 2.39 \mathrm{~mm}$ on the left side. Keros classification results on the right side were type 0 in $1(0.6 \%)$ patient, type 1 in $19(12.1 \%)$ patients, type 2 in $92(58.6 \%)$ patients and type 3 in $45(28.7 \%)$ patients. Keros classification results on the left side were type 0 in $3(1.9 \%)$ patients, type 1 in 23 $(14.6 \%)$ patients, type 2 in $82(52.2 \%)$ patients and type 3 in $49(31.2 \%)$ patients.

There was a significant negative correlation between the female gender and increased sphenoid sinus pneumatisation $(p=0.035)$. There was a positive correlation between maxillary sinus septa and the presence of Onodi cells ( $p^{\text {right }}=0.045, p^{\text {left }}=0.017$ ). There was also a negative correlation between presence of maxillary sinus septa and sphenoid pneumatisation classification $\left(p^{\text {right }}=0.001, p^{\text {left }}=0.005\right)$. There was a positive correlation between the presence of maxillary sinus septa on the right side with presence of right $(p$ $=0.007)$ and left sided Haller cells $(p<0.001)$. However, presence of maxillary sinus septa on the left side was positively correlated with the presence of only left Haller cells $(p=0.010)$. The presence of right sided bullous turbinate was positively correlated with right sided maxillary septation $(p=0.020)$, as well as with left sided maxillary septation $(p=0.004)$. Likewise, there was a positive correlation between the presence of maxillary septa and bullolamellar type concha bullosa on the right side $\left(p^{\text {right }}=0.024, p^{\text {left }}=0.046\right)$.

There was a positive correlation between the presence of Agger nasi cell on the right side and the presence of right sided and left sided maxillary septa ( $p^{\text {right }}$ $\left.=0.010, p^{\text {left }}=0.014\right)$. Similarly, there was a positive correlation between the presence of Agger nasi cells on the right side and the presence of Haller cells $\left(p^{\text {right }}\right.$ $\left.=0.002, p^{\text {left }}=0.018\right)$ on both sides. There was a correlation between the presence of Agger nasi cells on the left side and the presence of Haller cells on the right side $(p=0.002)$. There was a significant correlation between an increase in septation within the sphenoid sinus and increase in lateral lamellar height ( $p=$ $0.004)$. The presence of concha bullosa on both sides was positively correlated with the presence of Haller cells on the left side $\left(p^{\text {right }}=0.050, p^{\text {left }}=0.007\right)$.

There was no significant relationship between septal deviation and the presence or type of concha bullosa, Agger nasi, Haller cells, Onodi Cells, sphenoid sinus pneumatisation, paradoxical middle turbinate, maxillary sinus septa,vertical septa in the sphenoid sinus, optic nerve dehiscence and cribriform plate lamina lateralis height $(p>0.05)$.

\section{DISCUSSION}

The development of minimally invasive surgical techniques has made it essential to understand the anatomy of the paranasal sinus. Anatomic variations must be well understood to ensure patient safety and 
prevent surgical complications. Prior to performing FESS, PSCT is the gold standard imaging modality for the evaluation of patients [9]. Anatomical variations of the paranasal sinuses can cause various sinus pathologies and complicate surgeries. These variations include nasal septum deviations, concha bullosa, Agger nasi cells and Haller cells [10, 11].

Nasal septum deviationsare found in 20\%-79\% of the population $[2,4]$. Nasal septum deviations are usually observed in the lower part of the septum, near the chondrovomeral region. Severe septal deviations may lateralise the middle turbinate and make it difficult to access pathologies within the middle meatus during surgery. Septal deviations should be carefully evaluated to improve surgical vision in FESS [2].

Koo et al. [3] found that deviations towards the left side were slightly more common than deviations towards the right side $(43.9 \%$ and $36.4 \%$, respectively). At $52.9 \%$ of cases, deviation towards the left side was also more common in our study.In addition, according to the Mladina classification, class 5 deviations were the most common class of deviations with $55.1 \%$ of cases. At $46.5 \%$ of observed cases, anteroposterior deviations constituted the most common of the three locations for deviations. In our study, the chondrovemoral region was the most common site for deviations.

Agger nasi cells are the most anterior ethmoid air cells. Anterior ethmoid cells, particularly Agger nasi cells, can cause constriction or obstruction of the nasofrontal canal [12]. In several studies, the prevalence of Agger nasi cells varied between $61.4 \%$ and $98.5 \%$. However, in $90.6 \%$ of cases, the presence of agger nasi cells was bilateral $[4,13]$. Unlike other studies, agger nasi cells were found on the right side in $51 \%$ patients, on the left side in $51 \%$ of patients and on both sides in $47.1 \%$ of patients.In addition, patients with agger nasi cell had a higher incidence of Haller cells and maxillary septa.

Haller cells, first identified by Albrecht Von Haller in 1756 and named after him, are infraorbital ethmoid cells $[10,14]$. Zinreich and Kennedy described Haller cells as ethmoid air cells that adhere to the maxillary sinus ceiling and form part of the lateral wall of the infundibulum, inferior to the ethmoid bulla [4]. Khojastepour et al. [13] found a significant relationship between maxillary sinusitis and the presence of Haller cells. The presence of Haller cells may increase the risk of orbital injury during ethmoidectomy $[10,15]$. Bolger et al. [16] reported that they found Haller cells in $45 \%$ of cases examined via CT. Yücel et al. [4] found Haller cells in $18.5 \%$ of cases in their studies. The incidence of Haller cells reported in different studies range between $5.5 \%$ and $45.9 \%$ [10, 14]. In our study, Haller cells were found on the right side in $8.1 \%$ of patients, on the left side in $9.6 \%$ of patients and on both sides in $5 \%$ of patients. In addition, patients with maxillary sinus septa and agger nasi cell had a higher incidence of Haller cells.

The presence of Onodi cells reported in previous studies range between $0.4 \%$ and $14 \%[2,17]$. Onodi cells may predispose the optic nerve and the internal carotid artery to injury during surgery [1]. In our study, Onodi cell was observed in $23.6 \%$ of patients. While septation was not observed in the sphenoid sinus in $3.8 \%$ of patients, $70.1 \%$ of patients had 1 vertical septum, $19.1 \%$ of patients had 2 vertical septa and $7 \%$ of patients had 3 vertical septa.Type 1 sphenoid sinus pneumatisation was found in $47.1 \%$ of patients, $36.9 \%$ of patients had type 2 and $15.9 \%$ of patients had type 3 sphenoid sinus pneumatisation. Sphenoid sinus agenesis was not detected in our study. Female patients and patients with maxillary sinus septa had less sphenoid sinus pneumatisation. Onodi cells were found more frequently in patients with maxillary sinus septa. Both Onodi cells and septation in the sphenoid sinus occurred frequently in our study. We concluded that especially in FESS, caution should be taken to prevent complications due to regional proportional differences.In addition, we concluded that caution should be taken in patients with maxillary sinus septation, as there is a high rate probability of Onodi cells within the low pneumatised sphenoid sinus.

The optic nerve can be exposed on the roof of the sphenoid sinus up to $24 \%$ [2]. The optic nerve is often exposed in the superior-lateral wall of the sphenoid sinus between 8 to $100 \%$ rate [14]. In our study, optic nerve protrusion was detected in the sphenoid sinus at a rate of $26.8 \%$, comparable to figures in literature.Visual loss due to optic nerve injury is one of the most feared complications of endoscopic sinus surgery. Therefore, it is important to fully evaluate the radiological anatomy of the optic nerve before FESS [15].

Concha bullosa refers to the pneumatisation of the lower bulbous part of the middle turbinate. Concha bullosa occurs due to changes in the development of 
ethmoid air cell system. Concha bullosa can be unilateral or bilateral and can be classified into three types based on the site of pneumatisation. They are the lamellar type; pneumatised vertical lamellae of the middle turbinate, the bulbous type; pneumatised lower part of the middle turbinate and thetrue type; vertical lamella and pneumatised bottom of middle turbinate [18]. Concha bullosa occurs in approximately 13\%$55 \%$ of the population and is usually bilateral $[2,3$, 19]. The incidence of bilateral concha bullosa has been reported between $36.4 \%$ and $54.7 \%$ [3, 18]. It is a possible aetiological factor in recurrent chronic sinusitis [3]. In our study, the incidence of concha bullosa was $56.1 \%$ on the right side, $53.5 \%$ on the left side and $43.9 \%$ on both sides. In patients with right sided concha bullosa, $26.3 \%$ of them were lamellar, $4.5 \%$ of them were bullous and $22.3 \%$ of them were true. In patients with left-sided concha bullosa, $29.9 \%$ of them were lamellar, $2.5 \%$ were bullous and $22.3 \%$ of them were true.

The paradoxical middle turbinate is the convex side of the middle turbinate facing the lateral direction [4]. In the literature, the frequency of paradoxical middle turbinates ranges between $2.8 \%$ and $32 \%$ [1, 4 , 17]. The paradoxical middle turbinate is thought to cause recurrent rhinosinusitis and prevent access to the ostiomeatal unit during surgery [2]. Paradoxical middle turbinate can cause recurrent infundibular disease and sometimes headache $[13,20]$. In our study, the paradoxical middle turbinate occurred on the right side $12.1 \%$ of the time, on the left side $8.3 \%$ of the time and on both sides $5.7 \%$ of the time.

Secondary middle turbinate is an extra turbinate between the upper turbinate and the middle turbinate, with a projection between the lateral nasal wall and the middle meatus [5]. In their studies, Kaplan et al. [5] found that secondary middle turbinate occurred at a rate of about $6 \%$. Secondary middle turbinate was observed in $0.6 \%$ of patients in our study.

Septa in the maxillary sinus occur commonly and may be fibrous or bony. They usually extend from the infraorbital nerve canal to the lateral wall and may affect drainage of the maxillary sinuses [2]. In our study, maxillary sinus septation was seen on the right side $19.1 \%$ of the time, on the left side $21.7 \%$ of the time and in both sides $16.5 \%$ of the time. In addition, we found that the incidence of Agger nasi cells, Onodi cells, Haller cells and true type concha bullosa were higher in the presence of maxillary sinus septa. We also found that sphenoid sinus pneumatisation decreased in the presence of maxillary sinus septa. Abnormalities that may cause chronic sinusitis are more common in cases with maxillary sinus septa.

As described by Keros [7], there are three types of olfactory fossa, depending on the height of the lateral lamella of the cribriform plate. Type 1 refers to the shallow or flat olfactory fossa seen in $30 \%$ of cases and ranges between $1 \mathrm{~mm}$ and $3 \mathrm{~mm}$. Type 2, which indicates a moderate deep olfactory fossa and occurs in $49 \%$ of cases,ranges between $4 \mathrm{~mm}$ and $7 \mathrm{~mm}$. Type 3 ranges between $8 \mathrm{~mm}$ and $16 \mathrm{~mm}$ and is observed in $21 \%$ of cases [2]. Nouraei et al. [10] found Keros type 1 in $3.5 \%$, Keros 2 in $74 \%$ and Keros 3 in $22.5 \%$ of their cases. In our study, the mean height of the cribriform plate lamina lateralis was $6.1 \pm 2.18 \mathrm{~mm}$ on the right side and $5.88 \pm 2.39 \mathrm{~mm}$ on the left side. Given that the lateral lamella of the cribriform plate is the thinnest bone in the anterior skull base and is dehiscenced in $14 \%$ of patients, the risk of intraoperative injury and iatrogenic cerebrospinal fluid leakage is higher in this region [2]. Anterior skull base examination using $\mathrm{CT}$ should be performed by every surgeon before FESS to reduce risk ofcomplications [21]. In our study, we found that an increase in the height of the olfactory fossa was positively correlated withincreases in sphenoid septation. Both of these factors are risky anomalies during the FESS procedure. We though that these relationships should be considered during CT evaluation before FESS.

\section{CONCLUSION}

Several studies have shown a relationship between chronic sinusitis and paranasal sinus anomalies. Before endoscopic sinus surgery, evaluation of patients for anomaliesusing $\mathrm{CT}$ can reduce the intraoperative complications and increase procedural success. In our study, we found that maxillary sinus septa, Agger nasi cells, Haller cells, Onodi cells, cribriform plate lamina lateralis height and sphenoid sinus septation were interrelated. However, nasal septum deviation was not related to the aforementioned anomalies. We recommend that surgeons evaluate patients for these variations to prevent procedural complications. 


\section{Author contributions}

O.D. = Literature survey, design, planning, data collection, intellectual review of the results, writing, approving the final manuscript. O.D. = Literature survey, intellectual review of the results, writing, approving the final manuscript

\section{Conflict of interest}

The authors disclosed no conflict of interest during the preparation or publication of this manuscript.

\section{Financing}

The authors disclosed that they did not receive any grant during conduction or writing of this study.

\section{REFERENCES}

1. Şahin C, Yilmaz YF, Titiz A, Özcan M, Özlügedik S, Ünal A. [The Anatomic Variations of Paranasal Sinuses : Computerized Tomography Study]. KBB ve BBC Dergisi 2007;15:71-3. [Article in Turkish]

2. Vaid S, Vaid N. Normal anatomy and anatomic variants of the paranasal sinuses on computed tomography. Neuroimaging Clin N Am 2015;25:527-48.

3. Koo SK, Kim JD, Moon JS, Jung SH, Lee SH. The incidence of concha bullosa, unusual anatomic variation and its relationship to nasal septal deviation: a retrospective radiologic study. Auris Nasus Larynx 2017;44:561-70.

4. Yücel A, Dereköy FS, Yılmaz MD, Altuntaş A. [Effects of sinonasal anatomical Variations on paranasal sinus infections]. Kocatepe Tip Dergisi 2004;5:43-7. [Article in Turkish]

5. Kaplan Y, Müderris S, Kunt T. [Tomographic analysis of sinonasal variations and relationship with sinusitis]. C Ü Tip Fakültesi Derg 2004;26:29-36. [Article in Turkish]

6. Vaezi A, Cardenas E, Pinheiro-Neto C, Paluzzi A, Branstetter IV BF, Gardner PA, et al. Classification of sphenoid sinus pneumatization: relevance for endoscopic skull base surgery. Laryngoscope 2015;125:577-81.

7. Keros P. On the practical value of differences in the level of the lamina cribrosa of the ethmoid. Z Laryngol Rhinol Otol 1962;41:809-13.

8. Mladina R. The role of maxillar morphology in the development of pathological septal deformities. Rhinology 1987;25:199205.
9. Y1lmazsoy Y, Arslan S. Med HS. [Assessment of the prevalence of Haller cell variation and the relation between Haller cell variation and maxillary sinusitis]. J Health Sci Med 2018;1:548. [Article in Turkish]

10. Nouraei SAR, Elisay AR, Dimarco A, Abdi R, Majidi H, Madani SA, et al. Variations in paranasal sinus anatomy: implications for the pathophysiology of chronic rhinosinusitis and safety of endoscopic sinus surgery. J Otolaryngol Neck Surg 2009;38:32-7.

11. Daghighi M, Daryani A, Nejad KC, Daghighi M, Daryani A, Nejad KC, et al. Evaluation of anatomic variations of paranasal sinuses. Internet J Otorhinolaryngol 2012;7:7-11.

12. Lebowitz RA, Brunner E, Jacobs JB. The agger nasi cell: radiological evaluation and endoscopic management in chronic frontal sinusitis. Oper Tech Otolaryngol Head Neck Surg 1995;6:171-5.

13. Khojastepour L, Haghnegahdar A, Khosravifard N. Role of sinonasal anatomic variations in the development of maxillary sinusitis: a cone beam CT analysis. Open Dent J 2017;11(Suppl1, M5):367-74.

14. Efendić A, Muharemović E, Skomorac R, Bečulić H, Šestić $\mathrm{S}$, Halilović B, et al. Anatomic variations of posterior paranasal sinuses and optic nerve. Med Glas 2017;14:49-54.

15. Özer F, Çağıcı CA, Özer C, Kızılkılıç O, Yılmazer C, Özlüoğlu LN. [The progress of the optic nerve in the coronal paranasal sinus tomography]. Turk Otolarengoloji Ars 2013;47:15-20. [Article in Turkish]

16. Bolger WE, Butzin CA, Parsons DS. Paranasal sinus bony anatomic variations and mucosal abnormalities. Laryngoscope 1991;101:56-64.

17. Birkin T, Acar T, Esen Ö. [The anatomical variations of the sinonasal region and its relationship with sinus diseases]. Tepecik Eğit Hast Derg 2017;27:236-42. [Article in Turkish]

18. Kalaiarasi R, Ramakrishnan V, Poyyamoli S. Anatomical variations of the middle turbinate concha bullosa and its relationship with chronic sinusitis: a prospective radiologic study. Int Arch Otorhinolaryngol 2018;22:297-302.

19. Caversaccio M, Boschung U, Mudry A. Historical review of Haller's cells. Ann Anat 2011;193:185-90.

20. Shpilberg KA, Daniel SC, Doshi AH, Lawson W, Som PM. $\mathrm{CT}$ of anatomic variants of the paranasal sinuses and nasal cavity: poor correlation with radiologically significant rhinosinusitis but importance in surgical planning. Am J Roentgenol 2015;204:1255-60.

21. Kara A, Güven M, Yilmaz MS, Elden H, Demir D. [Keros classification and evaluation of cribriform plate depth asymmetry of the population in Marmara region]. Sakarya Med J 2018;8:352-8. [Article in Turkish] 